\title{
The charisma machine: The life, death, and legacy of one laptop per child
}

\author{
Morgan G. Ames. 2019. The MIT Press, Cambridge, MA. 328 pp. \\ Infrastructures series. ISBN 978-0-262-53744-5 (pbk)
}

\section{Hany Zayed ${ }^{1}$}

Published online: 28 April 2020

(c) UNESCO Institute for Lifelong Learning and Springer Nature B.V. 2020

The contemporary educational landscape has been witnessing a proliferation of technological interventions deemed radical, disruptive and transformational. In The Charisma Machine, Morgan Ames tells the story of one of the most prominent yet problematic modern educational technologies: the One Laptop Per Child initiative (OLPC). Founded in 2005 and touted as an educational project, OLPC sought to produce and distribute hard-to-break, low-power laptops fitted with software and content. The laptops were intended both for individual educational change and social change, and were thus offered to country governments in the Global South at low cost.

The Charisma Machine examines, complicates and problematises the OLPC project as it was implemented in Paraguay. This book tells a story of the clash between idealistic promises and messy realities, the disconnect between intended and unintended consequences, and the dangers of quasi-divine techno-fetishism and technosolutionism. In its two parts, the book traces the historical origins of OLPC, and explores the usage, impacts and legacy of its machines by following its signature "XO laptop" as well as the people who thought about it, designed it, distributed it and used it.

Before beginning her exploration, Ames lays the groundwork by introducing her central analytical anchor: charismatic technologies. Building on theoretical insights from Max Weber, "one of the founders of modern sociology" (p. 8), Ames conceives of a charismatic technology as one which "derives its power experientially and symbolically through the possibility or promise of action" (p. 10). Charismatic technologies tap into existing cultural mythologies, social imaginaries and ideological frameworks to promise a utopian vision, and persist against failed promises, contradictions, counterevidence, uncertainties, opposition and critique. Marked by

Hany Zayed

hanykz2@illinois.edu

1 University of Illinois at Urbana-Champaign, Urbana, IL, USA 
technological determinism wrapped in a transformatory rhetoric, they eliminate agency and make individual and social change seem natural and inevitable.

The first part of the book (chapters 1-2) offers an intellectual and cultural genealogy of OLPC. It examines the ideological scaffolding supporting OLPC and its charisma, and traces the materialisation of those ideas into the XO laptop. Through an analysis of OLPC-related speeches, discussions, publications and talks, in addition to interviews with OLPC contributors and observations of annual OLPC Community Summits, Ames argues that OLPC and its underpinning charisma emerged from and were rooted in the complementary union of constructionism (an education theory espousing the importance of programmable computers - and technology in general - in the active learning of children), the hacker culture emerging at the Massachusetts Institute of Technology (MIT) in the 1960s, and the social imaginary of the technically precocious boy (a gendered, anti-school, anti-teacher idea of a world where boys are imagined to be innately creative and rebellious, with a natural and intuitive mastery of technology).

Ames continues by showing how this learning theory, cultural ethos and social imaginary migrated to and became instantiated in the design of the XO laptop through what she calls "nostalgic design" (p. 47): design based on one's childhood memories and experiences with technologies. Concretely, this was reflected in features of play (the laptop's toy-like appearance and the focus on games), connectivity (the construction of mesh networks to enable easy laptop/internet connection) and freedom (free, open-source and easy-to-repair software and hardware). These features constituted the laptop's charisma and were integral to the promise not only of pedagogical change, but also of radical social transformation.

The second part of the book (chapters 3-6) is concerned with the usage and effects of the XO laptop in a medium-sized OLPC project in Caacupé, Paraguay. Skilfully employing a mixed methods approach, Ames conducted an ethnographic study in Paraguay for seven months between 2010 and 2013 where she observed classrooms, homes and public spaces, attended events, and conducted 144 interviews with a host of actors associated with the project. Ames also analysed laptop usage, breakage and repair statistics and attendance data, and designed and administered reading comprehension and mathematical reasoning exams.

Ames begins the presentation of her in-depth case study by exploring the labour needed to "translate" OLPC's promises to the Paraguayan reality by the NGO responsible for this project - Paraguay Educa. This process included digital infrastructure investments, teacher trainings and maintenance work. Yet, faced with structural constraints in terms of schools and teachers, this translation work proved "incomplete" (p. 108) and teachers were forced to endure the additional labour of solving technical difficulties, dealing with breakages and installing missing software. Naturally, this disrupted the educational process, limited teachers' agency and thus prompted many to stop using the laptops. Nonetheless, those who did try to continue using the laptops were confronted with another issue: usage. Overall, around twothirds of the laptops were unused: fifteen per cent due to breakage and half due to disinterest and operating difficulties. Enamoured by the internet, the remaining onethird of the children used the laptop not for the constructionist activities intended, but for media consumption: playing games, listening to music and watching videos. 
In chapter 5, Ames continues her exploration by following the lives of several technically precocious Paraguayan children considered exemplars of OLPC success. Yet, contrary to OLPC rhetoric that learning is an individual undertaking and that children can lift their communities from adverse structural conditions, Ames found that what guided the interests, development and education of these children were their social worlds, demonstrating that education is indeed a social process. Furthermore, Ames found that these children failed to dislodge their communities from structural inequalities and stood helplessly as existing socioeconomic, linguistic and gender divides were reproduced.

The final chapter introduces Ames's concept of charismatic performances: pretending to achieve successful and transformative results by invisiblising translation labour, breakages and the messiness of everyday life to ensure the flow of financial and social support. In her conclusion, Ames uses OLPC's failure to discuss the enduring legacy of charismatic technologies. She argues that OLPC was "nostalgized" by being relegated back to myth while its charisma lives on through other technologies.

The Charisma Machine provides a rigorous, rich, articulate and cross-disciplinary critical sociology of educational technologies. Through her compelling arguments, Ames offers a cautionary tale of educational technologies and transformational discourses, introduces novel and valuable theoretical interventions - particularly charisma - and exhibits an exemplary and imaginative use of methods that undoubtedly has potential to guide future researchers. In telling a story of messy realities and unintended consequences, Ames punctures the view that technology is natural, inevitable, smooth and unproblematic. She demystifies and scathingly critiques the assumption-ridden, historically ignorant, agency-occluding, value-laden, unsubstantiated, hyperbolic and colonial OLPC project. This includes the assumptions that computers are universally appealing, that children are natural yearners ${ }^{1}$ and that technology is a universal panacea, that the values of individualism and (cyber)libertarianism are desirable, and that the politically normative moorings of producing a (technically precocious) neoliberal entrepreneurial subject are laudable. In addition, by showing how learning is a social process, how the laptops were (mis)used and how they perpetuated existing inequalities, Ames reveals and disarms OLPC founders' asocial, apolitical and ahistorical reasoning, and shows how arrogant ignorance can have real consequences. Finally, through her findings of laptop usage patterns, Ames highlights the dangers of universalising a particular, historical and idiosyncratic experience/imaginary to others, and brings back the voice of the people to tell a story of (contained) agency.

Still, a number of points remain unanswered. First, this research has clear and important implications to a research community, particularly those interested in technological interventions in educational reforms, and those mostly are a Global

\footnotetext{
1 Inspired by Seymour Papert (1996), Ames uses this term throughout her book, explaining that “"yearner' [was] Papert's name for the kind of child who evoked the social imaginary of the technically precocious boy" (p. 111; see also p. 30). Papert, S, (1996). The children's machine: Rethinking school in the age of the computer. New York: Basic Books.
} 
North audience. ${ }^{2}$ Yet, it is not clear if and how the book affects the people of Paraguay - the objects of these 21 st-century colonial interventions. How can the book's insights help the students, families, teachers, NGOs and policymakers? Ames does offer the idea that incremental change grounded in a local context can be effective, so what could this change look like in Paraguay?

Second, there would still have been room to involve the Paraguayan context in the narrative. This would have included interrogating the literature on educational technologies emerging from Paraguay and exploring the social imaginaries, mythologies and ideologies particular to the Paraguayan milieu. And although Ames deftly contextualises her observations and findings spatially (by comparing them to OLPC projects in Peru and Uruguay), she could have explored whether historically similar projects were undertaken in Paraguay in general and in Caacupé in particular.

Finally, Ames is commendably reflexive of her positionality, the limitations that came with it and how she dealt with these, but she could have told us more about the legal (and bureaucratic) process of, and difficulties and surprises in, gaining access to schools.

By making both the familiar strange and the strange familiar, The Charisma Machine provides a much-needed, critical, robust and timely sociological work that brings forth important insights about technology, education and change, illuminates the operations and dynamics of techno-utopianism, moves away from structural inevitabilities, opens up space for agentic possibilities, and undeniably offers important lessons for future researchers.

Publisher's Note Springer Nature remains neutral with regard to jurisdictional claims in published maps and institutional affiliations.

\footnotetext{
${ }^{2}$ As the world wrestles with disruptions and uncertainties prompted by Covid-19, this book becomes more relevant with technology playing an increasingly tangled, constitutive and transformative role in education.
} 